social anthropology and material culture. The latter is the least changed of any in the book, a reflexion of the sound work done by the pioneers in this field. The section on social anthropology has become almost a text-book for the subject, which should be useful to the student as well as to the field anthropologist and to the amateur who is in need of guidance in the recording of material available to him. The definitions have been written into the text, and an attempt has been made to place the collection of data in relation to the problems which still require investigation. This is a great improvement on the old form of "Notes and Queries", which presented the investigator with a long list of imperative questions and left him to sort out for himself, if he could, why he should ask any or all. Some of the old formlessness still remains; but the field-worker can now feel that he has at last a guide to direct his work into meaningful fields rather than a formless checklist. It should lead to an improvement in field-work and in the publication of results.

A comparison of the new volume with the fifth edition, which appeared in 1929, illustrates the great advance that anthropological investigations have made in the intervening years, both in methods of field-work and in an understanding of the data collected. There is a demand for new types of information, and also for the collection of quantitative data and the use of proper sampling methods. These are welcome signs of the maturity which the subject has now reached. There is also evidence that the British social anthropologists are defining their field of study much more rigidly than in the past. No hint is given of the recent developments made by American anthropologists in the collection of data for the study of the influence of culture upon personality. There is no reference to the use of various projective tests, the collection of life-histories, or even the collection of dreams, although those responsible for the fifth edition considered this last a worthy field for investigation. This is an omission in a general guide to the field of anthropological investigation. The social anthropologists would probably justify the omission on the grounds that these studies belong to the field of psychology. This may be true, but field-workers are advised to pursue other investigations which seem equally to belong to the field of psychology, for example, "Observations of child behaviour in simple societies are of great value as checks on current psychological theories of child development. Thus theories concerning innate aggression, and aggression as a reaction to frustration, need to be checked by means of direct observation of infants and children in diverse cultures" (p. 101).

This is the only major omission. "Notes and Queries" in its new form should have a long and useful life.

\section{SCIENCE FOR NON-SCIENTISTS}

Science and Common Sense

By James B. Conant. Pp. xii 371. (London: Oxford, University Press, 1951.) 21s. net.

7 HE President of Harvard has obviously enjoyed himself in writing this book. He describes it as a work on the methods of science for the general reader, and so indeed it is; but he also says that nearly all the ideas and much of the technical material have been presented more than once in lectures to audiences of undergraduates. Moreover, the problem of teaching natural science as part of a general education has been actively and frequently discussed with his academic colleagues for a period of years.

Books on science for the layman are all too frequently written either by amateurs with no real qualifications for that difficult task, or by professional men of science who are not really able to think themselves into the frame of mind of the common man. Prof. J. B. Conant's book is something different, something which cannot be criticized on either ground - a book written by a man of science who obviously possesses not only exceptional qualifications and experience, but, as the reader soon discovers, a flair for imparting his knowledge divested of its technicalities. The non-scientific reader can almost believe that the author is 'one of us'. Appearances are deceptive. The old scientific hand will have no difficulty in detecting profound knowledge behind the simple explanations.

Science has become such an important element in our lives that it is no longer possible for the intelligent citizen either to ignore it or to leave it to the experts. Many non-scientific people in all walks of life are brought into daily contact with the results of scientific research and are called upon to determine policy and to make decisions on matters which are fundamentally scientific. It is Prof. Conant's thesis that, while it is obviously impracticable to give such people the full knowledge of science which scientific workers themselves possess, it is by no means impossible to teach them something of the 'tactics and strategy' of science; that is to say, to give them an under. standing of what goes on in scientific laboratories and of the methods by which scientific problems are attacked and solved.

The device he particularly advocates is the use of a series of 'case histories' ; and a considerable part of the book is devoted to Robert Boyle's work on pneumatics, Galvani's and Volta's discoveries in electricity, Pasteur's studies in fermentation, and many other great achievements in the progress of natural knowledge, used as illustrations of the manner in which science proceeds. The explanations of these steps in scientific history are illuminating; they have that completeness and freedom from ambiguity which comes only from a mastery of the subject.

Throughout the book the author's opinions are stimulating and provocative. There is, for example, his definition of science as "an interconnected series of concepts and conceptual schemes that have developed as a result of experimentation and are fruitful of further experimentation and observations". $\mathrm{He}$ will have none of science as the mere acquisition of knowledge. A piece of work is not true science if it does not lead to fresh ideas and further experiments. Then he crosses swords with all those who hold the belief that there is something which can be called a 'scientific method', with its implication that scientific workers are the only impartial inquirers. Not least interesting are his comments in the later chapters on some of the modern problems-the consequences of the replacement of independent investigators by research teams, the implications of the secrecy restrictions imposed by governments, science in the communist State, are examples of these.

The general reader, for whom it is intended, will learn much from this book; but his scientific friends will be well advised to borrow it from him.

Thomas Martin 